\title{
Percepção de discentes do Curso de Ciências Biológicas sobre o Zoológico de Fortaleza, Ceará
}

\author{
Perception of students of the Course of Biological Sciences on the Zoo of Fortaleza, Ceará \\ Percepción de los estudiantes del Curso de Ciencias Biológicas sobre el Zoológico de Fortaleza,
} Ceará

\begin{abstract}
Resumo
Esse trabalho avaliou a percepção de discentes do Curso de Ciências Biológicas de uma universidade pública de ensino, sobre o Zoológico de Fortaleza, Ceará. Foi aplicado questionário junto a 29 alunos da disciplina de Zoologia dos Cordados após aula de campo em 2017. Predominou nas análises, alunos do sexo feminino, que sabiam da existência do zoológico, já haviam visitado antes e com a família, reconheciam a importância da sua existência e apontaram servir para lazer e papel educativo. Como melhorias no bem-estar animal, destacou-se a ampliação e melhorias nos recintos. O maior aprendizado foi a vivência adquirida, chamando mais atenção os profissionais, funcionários e administração, e menos os recintos. Boa parte leem as placas informativas e todos ficaram satisfeitos com a visita. Na prática, fica claro que este ambiente atua como opção de lazer e promoção da educação ambiental, reforçando e despertando conhecimentos fundamentais para a formação dos futuros profissionais.
\end{abstract}

Palavras-chave: Espaço não formal; Ensino; Conservação da biodiversidade; Ensino superior.

\begin{abstract}
This work evaluated the perception of students of the Biological Sciences Course of a public university, about the Zoo of Fortaleza, Ceará. A questionnaire was applied to 29 students of the Cordados Zoo subject after a field lesson in 2017. In the analysis, female students, who knew of the zoo's existence, had visited it before and with their families, recognized the importance of its existence and pointed out to serve for leisure and educational role. As improvements in animal welfare, the expansion and improvements in the enclosures were highlighted. The greatest learning was the experience acquired, calling more attention to the professionals, employees and administration, and less the enclosures. Most of them read the information boards and everyone was satisfied with the visit. In practice, it is clear that this environment acts as a leisure option and promotion of environmental education, reinforcing and awakening fundamental knowledge for the training of future professionals.
\end{abstract}

Keywords: Non-formal space; Education; Conservation of biodiversity; University education.

\section{Resumen}

Este estudio evaluó la percepción de los estudiantes del Curso de Ciencias Biológicas de una universidad pública sobre el Zoológico de Fortaleza, Ceará. Se aplicó un cuestionario a 29 estudiantes de la disciplina de Zoología de los Cordados tras una clase de campo en 2017. En el análisis, predominaron las alumnas, que conocían la existencia del zoológico, lo habían visitado antes y con sus familias, reconocieron la importancia de su existencia y señalaron que 
sirve para el ocio y la función educativa. Como mejoras en el bienestar de los animales, se destacaron la ampliación y las mejoras en los recintos. El mayor aprendizaje fue la experiencia adquirida, y los profesionales, los empleados y la administración llamaron más la atención que los recintos. La mayoría leyó los carteles informativos y todos quedaron satisfechos con la visita. En la práctica, es evidente que este entorno actúa como opción de ocio y promoción de la educación ambiental, reforzando y despertando conocimientos fundamentales para la formación de los futuros profesionales.

Palabras clave: Espacio no formal; Educación; Conservación de la biodiversidad; Educación superior.

\section{Introdução}

Zoológico é descrito como qualquer coleção de animais silvestres mantidos vivos em cativeiro ou em semiliberdade e expostos à visitação pública, de acordo a lei № 7.173, de 14 de dezembro de 1983, instituída pelo Congresso Nacional do Brasil (Brasil, 1983). Estes ambientes são constituídos de fauna silvestre local e exótica, entretanto sofreram mudanças no decorrer do tempo, inicialmente eram espaços para diversão dos faraós no antigo Egito, que usavam das brigas entre os animais como forma de entretenimento, ou até mesmo como coleções observadas pela classe mais rica, e passando à concepções mais atuais que englobam princípios de conservação e bem-estar animal (Greif, 2017; Azevedo \& Barçante, 2018).

Com o passar dos anos, os zoológicos, distribuídos em todo o mundo, ganharam importância e adquiriram novas funções e ressignificações quanto ao cuidado animal e pesquisas. Igualmente, passaram a ser um recurso notório para o processo de educação ambiental, direcionados à realização de atividades práticas e didáticas com ações educativas de cunho ambiental (Goldschmidt, 2017; Artigas \& Fischer, 2019). Seu potencial educativo decorre de visitas cotidianas, trabalhos com conservação e biodiversidade, apresentando a importância da diversidade e do bem estar-animal para os frequentadores (Marin et al., 2017).

Para a Associação Mundial de Zoos e Aquários, a principal atribuição de atuação e visibilidade de um zoológico é a educação, pois abrange desde visitantes a escolas (Waza, 2005/2015), e isto também é reforçado por pesquisadores da área (Clayton et al., 2009; Patrick et al., 2010; Martins, 2012; Farinon et al., 2014). Estes equipamentos são considerados espaços não-formais de educação. Ambientes não-formais são delimitados como instrumentos de conservação, educação e pesquisa, expandindo as concepções de educação, não se limitando ao ambiente escolar (Pivelli, 2006). Estes locais podem ser utilizados em aulas práticas ou visitas de campo bem como, podem proporcionar discussões sobre as mais variadas temáticas, funcionando como um incremento para aulas e como ferramenta de reflexões sobre fauna e flora (Saraiva, 2017).

Neste sentido, analisando o contexto educacional, as visitas em zoológicos como atividades oferecidas nos cursos de ensino superior de Ciências Biológicas, por exemplo, podem ser fundamentais para a formação dos discentes, uma vez que auxiliam na construção do conhecimento interdisciplinar, e favorecem o desenvolvimento de uma mentalidade de preservação e conservação da biodiversidade (Affonso et al., 2015). Um mecanismo eficiente nesta perspectiva é a percepção ambiental, pois contribui para a sensibilização dos visitantes e pode resultar na conservação do ambiente (Zago et al., 2020).

À vista disso, o presente trabalho tem como objetivo avaliar a percepção de discentes do Curso de Licenciatura em Ciências Biológicas de uma universidade pública de ensino, sobre o Zoológico Municipal Sargento Prata, situado em Fortaleza, Ceará, Brasil.

\section{Metodologia}

A pesquisa realizada é de natureza descritiva (Prodanov \& Freitas, 2013), sendo qualitativa/quantitativa (Brasil et al., 2017), e foi desenvolvida durante visitas ao Zoológico Municipal Sargento Prata, junto a 29 alunos de graduação do Curso de Licenciatura em Ciências Biológicas da Universidade Estadual do Ceará (UECE), Campus do Itaperi, que se encontravam devidamente matriculados na disciplina de Zoologia dos Cordados, realizada nos semestres 2016.2 (junho/2017) e 2017.1 (novembro/2017). 
A área de estudo fica localizada no Parque Zoobotânico de Fortaleza, que compreende tanto o Zoológico, como o Horto Florestal Municipal Falconete Fialho, situada no bairro Passaré, em Fortaleza-CE (Figura 1).

A visita teve o intuito de apresentar aos estudantes o zoológico, visualizar a fauna presente, saber como funciona a rotina de trabalho e cuidados no ambiente, e refletir sobre sua existência e importância (Figura 2).

Após a realização da visita, os discentes foram convidados a participarem da pesquisa. Para coleta de dados utilizouse um questionário. Este continha 7 perguntas objetivas (simples e/ou de múltipla escolha) e 8 perguntas discursivas. As perguntas abordavam: idade, sexo, semestre, questionamentos gerais sobre o Zoológico Municipal Sargento Prata e a visão dos alunos sobre os zoológicos. A escolha do questionário como metodologia de coleta, ocorreu devido a maior facilidade e rapidez de adquirir dados, permitindo obter atitudes e opiniões dos participantes sobre determinado assunto, com baixo custo benefício e garantindo anonimato (Rosa, 2010; Chaer et al., 2011). Para garantir a análise ética dos dados, os alunos assinaram um Termo de Consentimento Livre e Esclarecido - TCLE.

Figura 1. Mapa do Parque Zoobotânico de Fortaleza, com ênfase para o Zoológico Municipal Sargento Prata, em FortalezaCE.
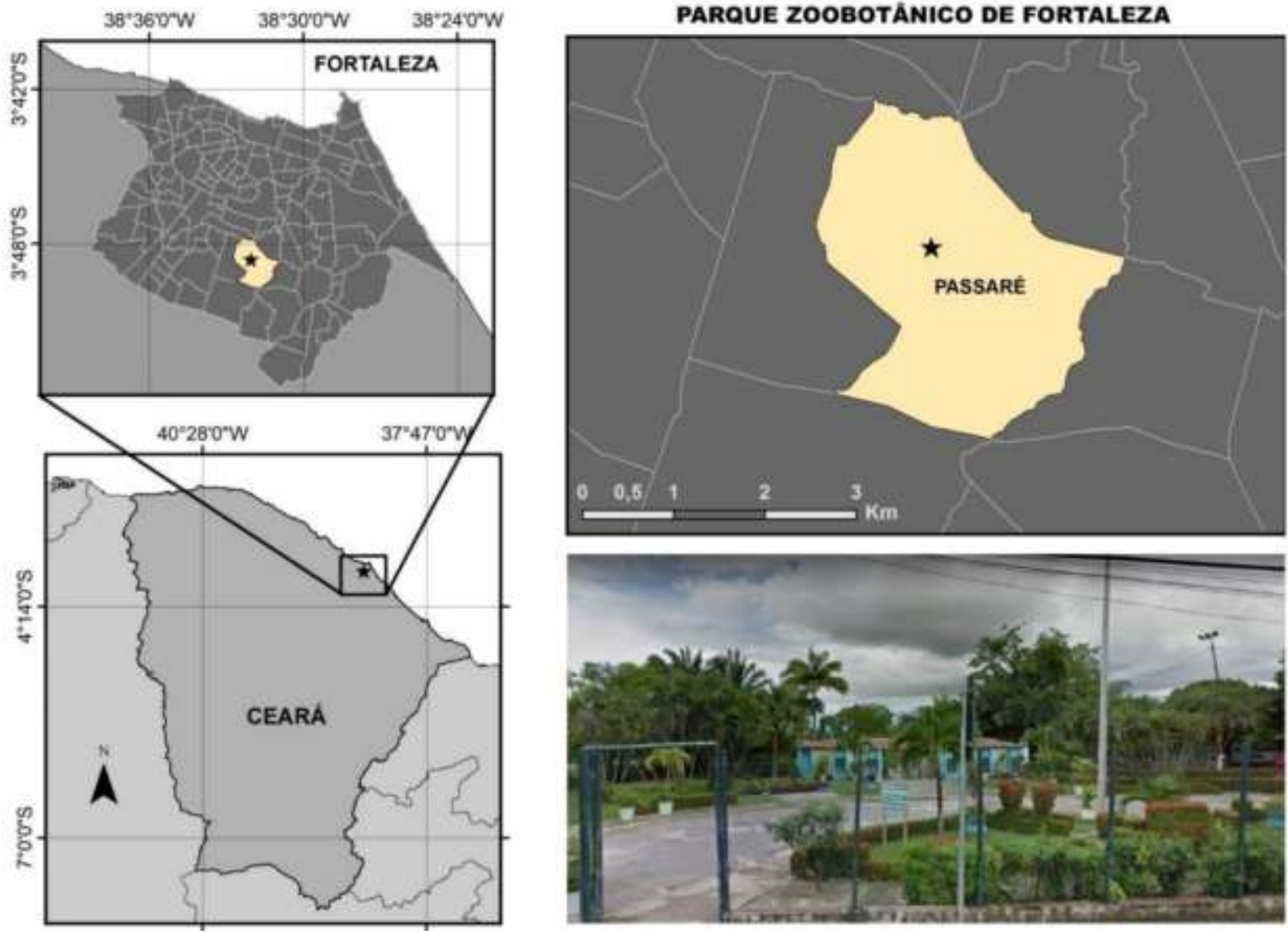

Fonte: Adaptado do Instituto de Pesquisa e Estratégia Econômica do Ceará - IPECE. 
Figura 2. Alunos durante a visitação ao Zoológico Municipal Sargento Prata, em Fortaleza-CE.



Fonte: Autores (2017).

Para a tabulação dos dados, foi utilizado o Google Formulários, e após análise, confeccionados gráficos a partir do programa Microsoftß Excel 2013 para as questões objetivas. Já para as subjetivas, foi usada a análise de conteúdo do tipo classificatória, segundo a metodologia de Bardin (2016).

\section{Resultados e Discussão}

Em relação ao perfil geral dos 29 alunos que participaram da pesquisa, obteve-se que $65,51 \%$ pertencem ao sexo feminino e $34,48 \%$ ao masculino, com faixa etária entre 20 e 32 anos de idade, e abrangendo o $5^{\circ}(37,93 \%), 6^{\circ}(34,48 \%), 7^{\circ}$ $(20,68 \%), 8^{\circ}(3,44 \%)$ e $9^{\circ}(3,44 \%)$ semestres.

Quando questionados se sabiam da existência do Zoológico Municipal Sargento Prata antes da visita realizada, 86,2\% afirmaram que sim e 13,8\% que não. Se já haviam visitado o zoológico, 51,7\% dos alunos afirmaram que não, 34,5\% que sim antes de ser fechado e 13,8\% que sim, depois de ser reaberto.

O presente zoológico existe no município de Fortaleza, desde o ano de 1979, contudo, devido a problemas de documentação referente a questões estruturais e administrativas, o mesmo foi interditado em 2013, e reaberto em 2016, com novas melhorias e adequações (Prefeitura de Fortaleza, 2016). O zoológico representa atualmente um importante local de lazer para a capital cearense e tem acesso totalmente gratuito, recebendo cerca de 21 mil visitantes a cada mês (O Povo, 2017).

Quanto às circunstâncias em que os alunos visitaram o zoológico, foram citadas visitas com a família $(78,57 \%)$, com os amigos (7,14\%), eventos ofertados pela universidade (7,14\%) e em visitas com alunos do colégio que lecionam $(7,14 \%)$. O espaço do zoológico em questão já se destaca como uma opção atrativa e agradável para familiares, assim como relatou Silva (2017) em seu estudo, que em diferentes momentos foram avistadas famílias realizando atividades de piqueniques ou passeios durante os turnos da manhã e tarde. Esta autora cita ainda que por ser um local aberto a todos, garante pluralidade social e cultural entre os visitantes. O mesmo cenário pode ser observado em outros lugares, como exemplo, Balleste (2019) afirmou 
que em sua pesquisa executada com 96 visitantes do Parque Zoológico da Fundação Zoobotânica do Rio Grande do Sul, 96,8\% destes estavam acompanhados de familiares e 3,1\% com amigos.

A própria UECE, por intermédio de entidades como Programas de Educação Tutorial (PET), empresas juniores e centros estudantis promove atividades e cursos em parceria com o zoológico, o que justifica algumas respostas dos participantes. Assim como é comum a visita de turmas de estudantes de diferentes escolas, que ocorrem de forma agendada como meio de controle e maior assistência por parte da gerência do zoológico.

Ao serem indagados se achavam importante a existência dos zoológicos, 89,65\% afirmaram que sim e 10,34\% que não (Quadro 1). Dentre as respostas positivas, observou-se prevalência de questões voltadas para a importância dos zoológicos na educação ambiental, preservação e conservação dos animais cativos. Antunes et al. (2017) analisou em seu trabalho a percepção ambiental de visitantes do Zoológico de Recife, e obteve que 97,5\% afirmaram que sim, a existência do zoológico é necessária, pois é uma área de preservação das espécies. Já de acordo com Fischer et al. (2017), o ponto principal que justifica a manutenção dos zoológicos é a busca da população por um ambiente de lazer, recreação, aprendizagem e oportunidade de conhecimento e interação com os diferentes animais.

Quadro 1. Algumas respostas extraídas dos questionários referentes a pergunta se os alunos acham importante a existência dos Zoológicos.

\section{Bloco A (89,65\%) - Sim, a existência de zoológicos é importante}

- “... os Zoológicos são um importante meio de implantação da educação ambiental, uma forma de aproximar as pessoas dos animais, de fazer com que o público leigo entenda que os animais têm necessidades e particularidades e que necessitam de um ambiente em equilíbrio... trazer para o cotidiano das pessoas essa realidade, faz com elas sejam sensibilizadas e conscientizadas dos impactos causados pela antropização nos ambientes naturais..." (Aluno 2)

- “... são de fundamental importância, porque, juntamente com outros órgãos como o Ibama e o CETAS, acolhem animais para serem tratados de maneira adequada, dando suporte e abrigo a eles...” (Aluno 10)

- “... para podermos ter noção da diversidade (mesmo que com poucos exemplares de poucas espécies) dos animais, e a importância da preservação destes" (Aluno 11)

Bloco B (10,34\%) - Não, a existência de zoológicos não é importante

- “... sou a favor da reabilitação do animal para retornar a natureza, caso isso não seja possível, colocá-lo em um zoológico não é uma medida ideal, é muito estressante para o animal estar convivendo com visitações do público" (Aluno 17)

- “... não acredito que o foco seja conservação" (Aluno 23)

Fonte: Autores (2021).

No entanto, esta questão divide opiniões, como é o caso dos discentes que discordam da importância da existência de zoológicos. Este caráter pode estar relacionado a fatores históricos de imagem e percepção destes ambientes, uma vez que eram apresentados como locais de exploração e exposição de um acervo vivo. Isto pode ser observado também no trabalho de percepção desenvolvido por Lima e Bosa (2016), com pais e filhos visitantes de parque em Curitiba, que afirmaram ser a exposição de animais a atividade menos importante do local.

Na sequência, foi indagado aos sujeitos da pesquisa quais as serventias de um zoológico, e obteve-se que é um lugar principalmente para lazer (72,4\%), conservação (69\%) e estudos (62,1\%) (Figura 3). Ao mesmo tempo em que se questionou qual o seu papel, havendo mais destaque para educação (89,7\%), conservação (82,8\%) e lazer (51,7\%) (Figura 4). Silva (2016) encontrou que os Zoológicos são importantes principalmente para o lazer (25\%), educação (22,47\%) e conservação $(22,78 \%)$. $\mathrm{O}$ autor afirma também que os animais mantidos nesses locais são importantes para a sua preservação, estudo e pesquisa e atividades de educação ambiental. 
Figura 3. Questionamentos referente ao para que serve os zoológicos.

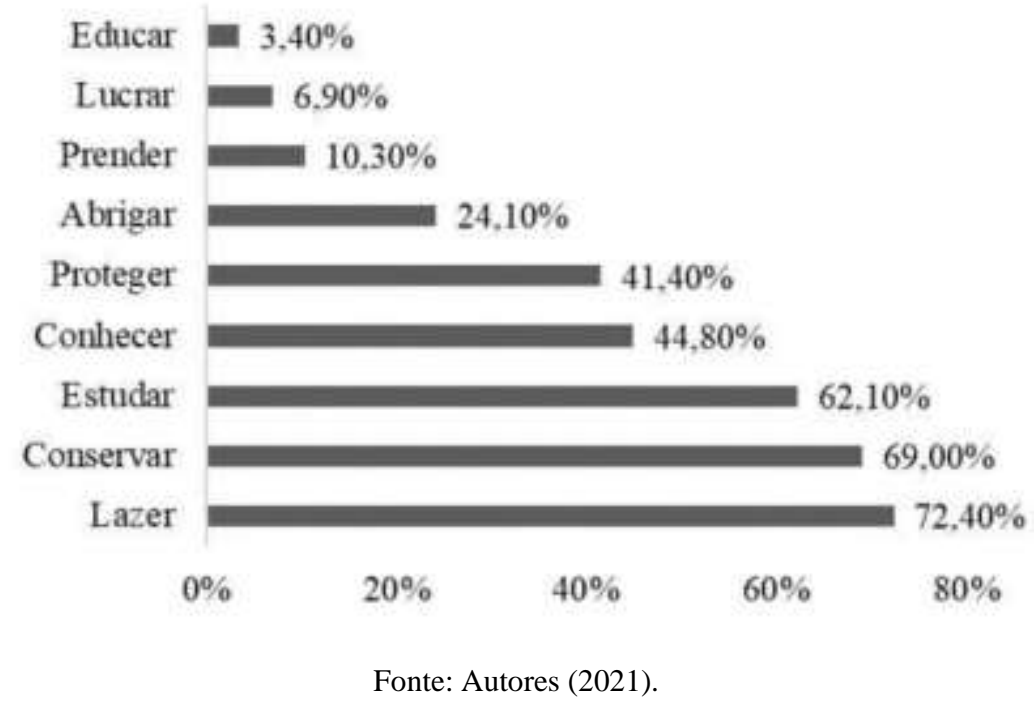

Figura 4. Questionamentos referente a qual o papel dos zoológicos.

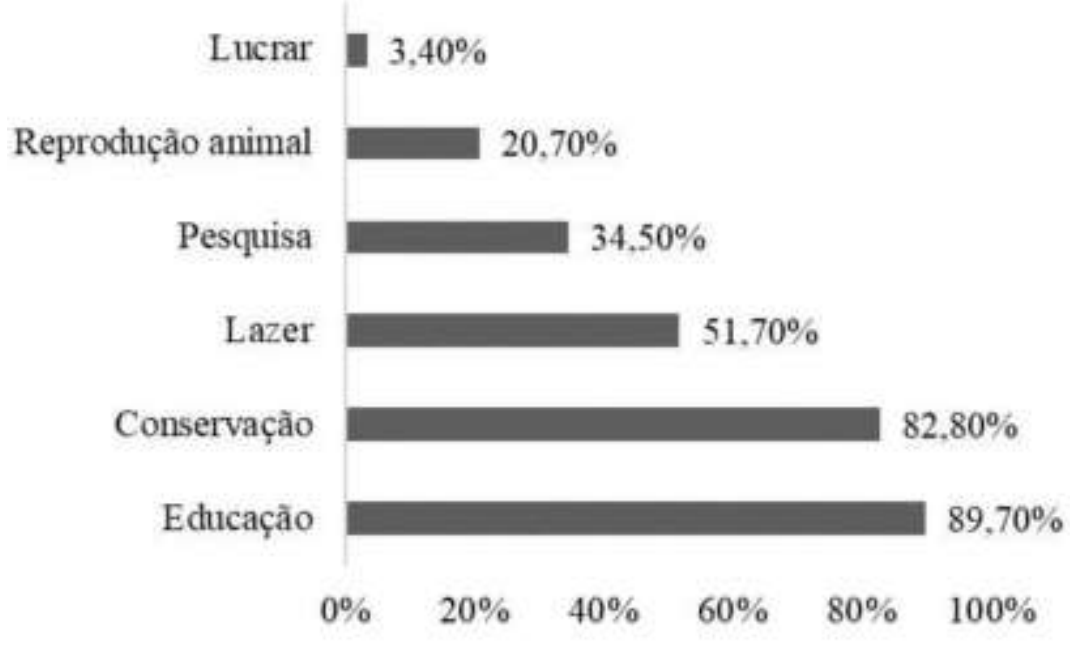

Fonte: Autores (2021).

Nota-se a partir disso, que as principais perspectivas estiveram voltadas à um espaço de lazer, conservação e educativo. De fato, assim como ratifica Goldschmidt (2017), os zoológicos devem ir além da concepção de exposição de fauna e flora, atuando também como ambiente educativo de informação quanto aos riscos e ameaças da retirada de determinado indivíduo do seu ambiente natural e comércio ilegal de animais silvestres, por exemplo. A autora ainda ressalta a importância da sensibilização ocorrida nestes momentos por meio da visualização de espécies ameaçadas de extinção, com máxima ambientação natural e devidas informações científicas.

Segundo Gomes (2012) além de práticas de educação ambiental, esses ambientes também são utilizados para pesquisa, porém essas atividades ainda são pouco realizadas. Analisando o contexto da pesquisa científica nestes espaços, é possível estudar, conhecer e acompanhar os comportamentos, hábitos, saúde e outras particularidades dos animais cativos, o que ajuda no conhecimento da ecologia das espécies, sua preservação e/ou possível reintrodução na natureza (Leira et al., 2017; Berico et al., 2018; Silva, 2019), sem contar que são bancos de dados de material genético de espécies ameaçadas de extinção e que são identificados e estudados através de parcerias com pesquisadores e instituições de ensino superior (Souza et al., 2020). Martins (2018) afirma que apesar dos zoológicos não serem espaços ideais para que os animais expressem suas 
características ambientais naturais, eles representam importantes fontes de informações sobre a biologia das espécies, o que favorece também na melhoria do seu bem-estar, além disso, eles podem fornecer dados importantes para o conhecimento e controle de doenças infecciosas emergentes que acometem certas espécies animais e que podem vir a ameaçar a saúde humana (Robinette et al., 2017).

O Zoológico Municipal Sargento Prata apresenta aproximadamente 45 espécies e 140 animais dentro dos grupos de répteis, mamíferos e aves (Silva, 2018). Além disso, o zoológico busca dispor de espaços de lazer e convivência, o que garante maiores atrativos e bem-estar aos visitantes, como a sala de educação ambiental, parquinho infantil e áreas arborizadas. Convém ressaltar também que abrangendo o local, há o Horto Florestal Municipal Falconete Fialho, espaço aberto e que é responsável pela produção, cultivo e fornecimento de plantas para o paisagismo das ruas, avenidas e equipamentos públicos de Fortaleza, com enfoque para plantas nativas da Caatinga, além de medicinais (Prefeitura de Fortaleza, 2018).

Sobre o que deveria haver no zoológico para melhorar a qualidade de vida dos animais, os alunos relataram a ampliação e melhorias nos recintos (62,06\%) e enriquecimento ambiental (37,93\%) (Figura 5).

Figura 5. Respostas dos participantes da pesquisa sobre o que deveria haver no zoológico para melhor a qualidade de vida dos animais.

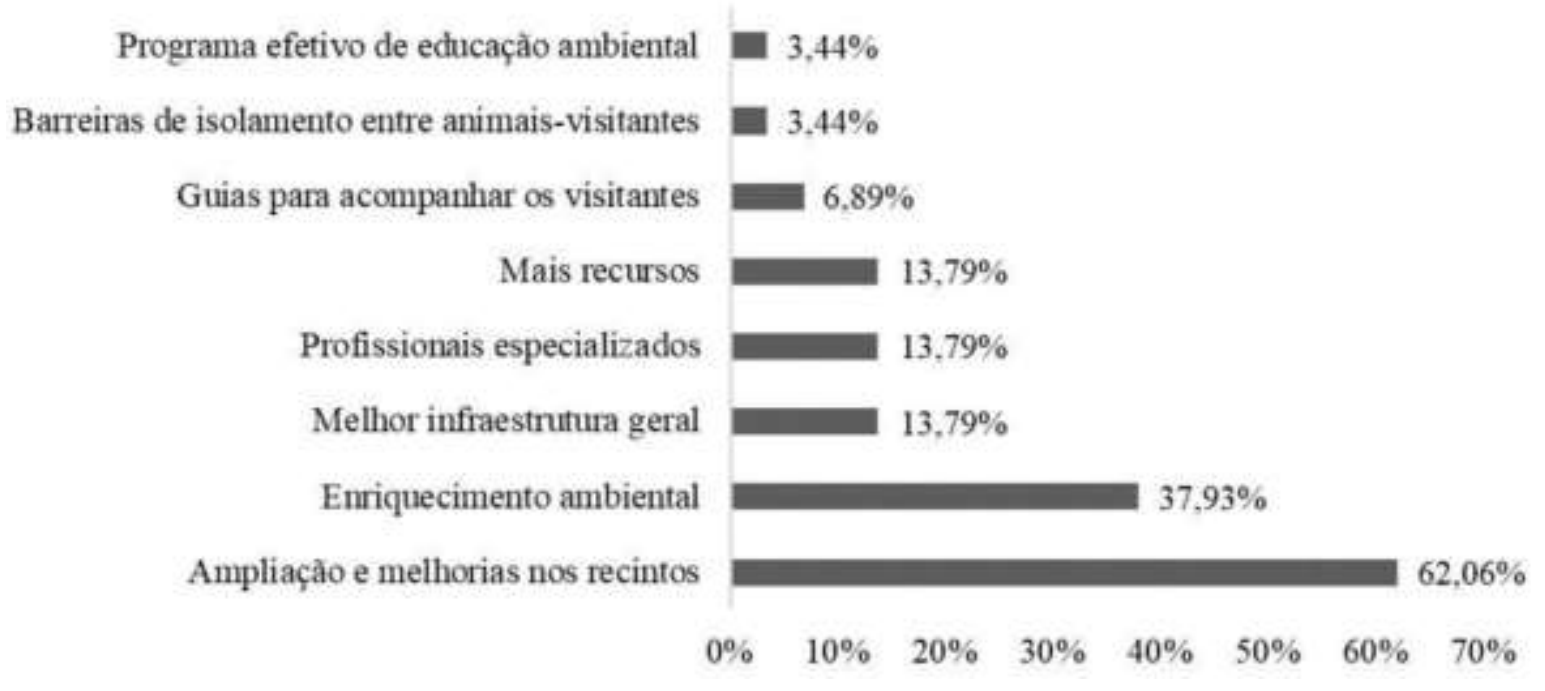

Fonte: Autores (2021).

Para a reabertura do Zoológico Municipal Sargento Prata em 2016, autoridades competentes e gerências do espaço buscaram a regularização das problemáticas encontradas com todas as normas necessárias para adequação e funcionamento dentro da legalidade, inclusive quanto aos recintos que passaram a ser atendidos pelo que exige a normativa $\mathrm{N}^{\circ} 07$ de 30 de abril de 2015 do Instituto Brasileiro do Meio Ambiente e dos Recursos Naturais Renováveis - Ibama (Brasil, 2015). Esta readequação e melhorias nos recintos também foi comprovada em estudo feito por Silva (2017).

O zoológico em questão já implementa medidas de enriquecimento com os animais cativos, com a ambientação de recintos e realização de atividades, com ênfase para aves e mamíferos, uma vez que estes animais são priorizados por possuírem comportamentos estereotipados, ou seja, repetitivos e obsessivos (Silva, 2018; Nojoza, 2019). O enriquecimento ambiental é um recurso com comprovada importância e eficiência quanto à redução do nível de estresse e inatividade dos animais em cativeiro, garantindo melhor qualidade de vida (Veroneze et al., 2020).

Neste estudo, por se tratar de um público voltado à área ambiental, e que possui afinidade para com os animais, é esperado que a preocupação e cuidados com o seu bem-estar seja mais evidenciado. Entretanto, Artigas e Fischer (2019) 
identificaram que os visitantes do Zoológico de Curitiba conseguem naturalmente perceber que os recintos necessitam de maiores estruturas para atender melhor os animais, ou seja, mesmo pessoas que não possuem conhecimento prévio e/ou técnico sobre o bem-estar animal, reconhecem as demandas essenciais com base nas necessidades das espécies.

Ainda sobre o mesmo questionamento, na sequência de impressões, os discentes destacam a melhor infraestrutura geral, profissionais especializados - biólogos, veterinários e zootécnicos e mais recursos com 13,79\% (Figura 5), como aspectos que também devem haver no zoológico para melhorar a qualidade de vida dos animais. Tais pontos estão diretamente relacionados à limitações financeiras presentes não só no zoológico em evidência, mas nos demais situados no estado do Ceará (Nojoza, 2019).

No que se refere ao aprendizado adquirido pelos estudantes ao saírem do zoológico, há maior destaque para a vivência como forma de aprendizado (48,3\%) e respeito pelos animais (34,5\%) (figura 6). Como já mencionado anteriormente, o zoológico possui uma rica diversidade de espécies, e com o tempo passa a receber ainda mais animais (Prefeitura de Fortaleza, 2019). Esta diversidade de espécies se torna fundamental para o conhecimento e aprendizado na prática por parte de discentes de biologia, como é o caso dos participantes desta pesquisa, principalmente tratando-se de um curso de licenciatura, na qual são formados professores que poderão futuramente compartilhar estas experiências e garantir a mesma vivência aos seus alunos. Prado e Teotonio (2020, p. 40), aduz que 'a visita técnica ao Zoológico possibilita a vivência de situações que não seriam possíveis em sala de aula e oferece uma grande diversidade de conhecimento".

Figura 6. Questionamento às indagações sobre o aprendizado adquirido pelos estudantes ao saírem do zoológico.

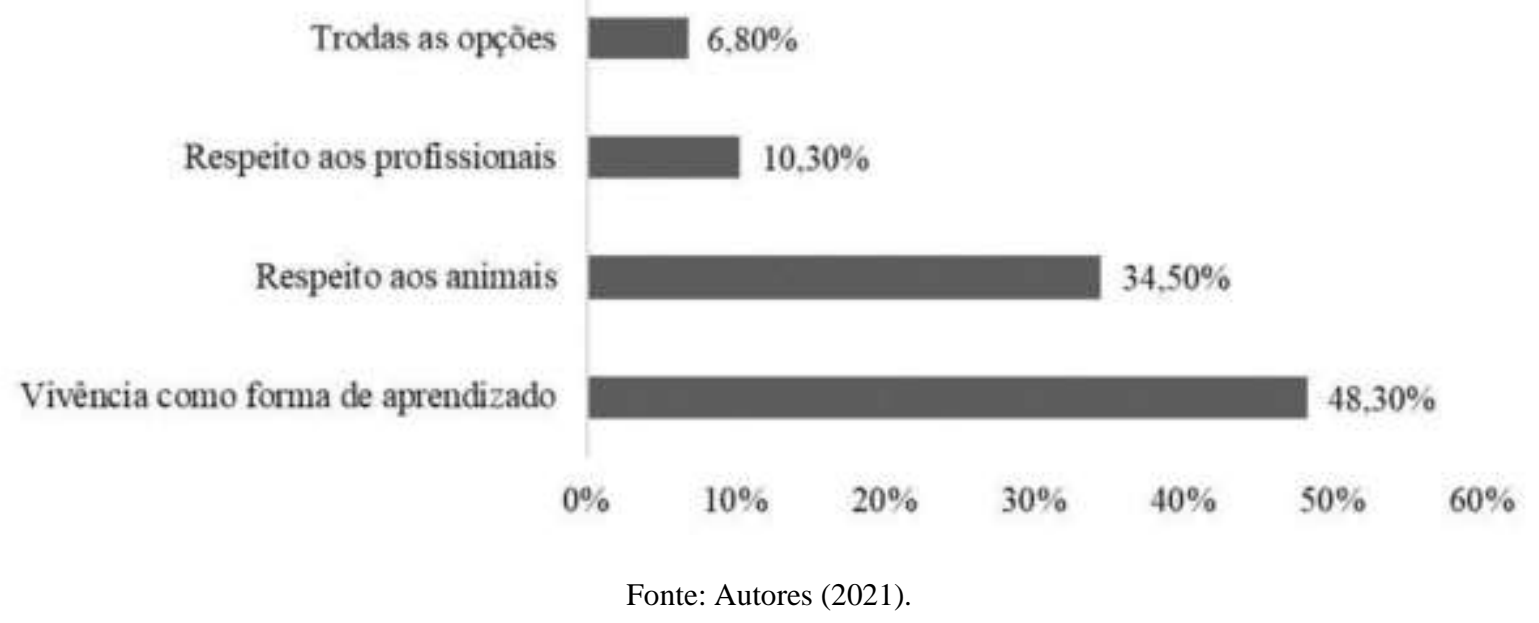

Um dos objetivos do zoológico é trabalhar a educação ambiental com seus visitantes, neste caso, através da visualização, contato e conhecimento dos animais, estes podem ser os principais fatores que despertaram e/ou reforçaram o respeito dos discentes pelas espécies encontradas. Lima et al. (2015) menciona que os visitantes do Parque Zoobotânico Dr. Mário Frota, em Minas Gerais, aprenderam que os animais precisam ser preservados, que muitos estão em extinção e a respeitá-los. Assim como Orso, Ferreira e Kufner (2017, p. 6) ao afirmarem que "a preocupação pelo respeito, necessidades, interesses e comodidade dos animais em cativeiro deve ser prioridade".

Sobre o que mais chamou a atenção dos alunos no Zoológico Municipal Sargento Prata, diante da análise de conteúdo, obteve-se positivamente: os profissionais, funcionários e administração do zoológico (Bloco A1 - 58,62\%), recintos e área do zoológico (Bloco B1 - 27,58\%) e fauna (Bloco C - 13,79\%); e negativamente: recintos e área do zoológico (Bloco A2 75,86\%) e os profissionais, funcionários e administração do zoológico (Bloco B2 - 24,13\%) (Quadro 2). 
Quadro 2. Algumas respostas extraídas dos questionários referentes a pergunta sobre o que mais chamou positivamente e negativamente a atenção dos alunos no Zoológico.

\begin{tabular}{|c|c|}
\hline Pos & \\
\hline \multirow{2}{*}{ 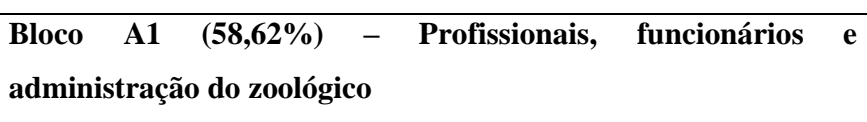 } & \multirow{4}{*}{$\begin{array}{l}\text { Bloco A2 (75,86\%) - Recintos e área do zoológico } \\
\text { - "Zoológico aparenta realizar pouco enriquecimento ambiental } \\
\text { com os animais" (Aluno 3) } \\
\text { - "Barulho me incomodou bastante. Não gostei porque alguns } \\
\text { animais (aparentemente) queriam descansar e pareciam } \\
\text { incomodados com o barulho dos visitantes (principalmente } \\
\text { crianças). O recinto da jaguatirica, por exemplo, era do lado do } \\
\text { parquinho e, como é um animal noturno, isso me pareceu errado" } \\
\text { (Aluno 10) } \\
\text { - "Recintos pequenos e consequente proximidade excessiva de } \\
\text { visitantes, o que com certeza estressa os animais" (Aluno 26) }\end{array}$} \\
\hline & \\
\hline $\begin{array}{l}\text { - "Trabalho dos funcionários em manter o equipamento } \\
\text { funcionando, o esforço dos responsáveis técnicos e dos demais, que } \\
\text { estão há tanto tempo tentando melhorar o zoológico" (Aluno 2) } \\
\text { - "Segurança e formação da bióloga responsável pelo zoológico" } \\
\text { (Aluno 9) } \\
\text { - "Informações sobre os animais, o cuidado que os tratadores têm } \\
\text { com os animais, profissionalismo e responsabilidade dos } \\
\text { profissionais" (Aluno 21) }\end{array}$ & \\
\hline Bloc & \\
\hline $\begin{array}{l}\text { - "Área preservada" (Aluno 6) } \\
\text { - "Gostei dos recintos, pois eram maiores que o de outros }\end{array}$ & $\begin{array}{l}\text { Bloco B2 }(24,13 \%)-\text { Profissionais, funcionários } \text { e } \\
\text { administração do zoológico }\end{array}$ \\
\hline $\begin{array}{l}\text { zoológicos que já fui. O jardim zoológico era espaçoso e } \\
\text { arborizado, e também tinha uma boa estrutura com sala de } \\
\text { atendimento veterinário, cozinha para preparo dos alimentos dos } \\
\text { animais" (Aluno 10) } \\
\text { - "Áreas verdes com locais para se reunir com outras pessoas" } \\
\text { (Aluno 16) }\end{array}$ & $\begin{array}{l}\text { - "Burocracia para contratar estagiários e implantar melhorias" } \\
\text { (Aluno 2) } \\
\text { - "Falta de recursos e infraestrutura" (Aluno 17) } \\
\text { - "Poucos trabalhos voltados para a educação ambiental dentro do } \\
\text { zoológico" (Aluno 27) }\end{array}$ \\
\hline Bloce & \\
\hline $\begin{array}{l}\text { - "Possibilidade de reprodução" (Aluno 1) } \\
\text { - "Diversidade de animais" (Aluno 4) } \\
\text { - "Maior diversidade de aves do que répteis e mamíferos" (Aluno } \\
\text { 22) }\end{array}$ & \\
\hline
\end{tabular}

Fonte: Autores (2021).

Duas categorias se repetem nas análises positivas e negativas quanto à maior atenção dos participantes, em especial no que diz respeito aos blocos A1 e B2. Percebe-se que os discentes reconhecem o trabalho e esforços da equipe de profissionais e administração do zoológico para manter e garantir o bem-estar dos animais e dos atrativos locais, ao mesmo tempo em que apontam falhas acerca da falta de recursos e infraestrutura, o que reflete em outros aspectos citados como a contratação de estagiários e a pouca promoção de educação ambiental para atender a demanda existente de visitação.

As categorias B1 e A2 também reúnem argumentos dentro do mesmo contexto, explanando questões positivas sobre os recintos e as áreas do zoológico, discussões estas, já mencionadas anteriormente. Vale evidenciar neste momento, que assim como informado pelos estudantes no bloco B1, diante da reabertura do equipamento em questão, ocorreram diversas benfeitorias e readequações no local, a saber: atualização do projeto arquitetônico e executivo; cadastro de acervos e documentações; ambulatório veterinário; contratação de biólogo, veterinário e zootecnista; equipamentos de contenção animal; nutrição de animais; sala de necrópsia; parque infantil; e sistema de segurança (Prefeitura de Fortaleza, 2016).

O bloco $\mathrm{C}$, abrange somente características positivas corresponde à fauna, e tratando do que compete à realidade do zoológico, que além do bem-estar, o próprio busca manter a diversidade de espécies no ambiente, recebendo por exemplo 70 animais em 2019, e também abrigando 30 espécies resgatadas pela Superintendência Estadual do Meio Ambiente (Semace) e 
pelo Ibama no mesmo ano (Prefeitura de Fortaleza, 2019; O Povo, 2019). A possibilidade de reprodução, apontada pelo Aluno 1 também ocorre na atualidade, na qual no ano de 2020, houve o nascimento de uma arara-vermelha, espécie ameaçada de extinção (Prefeitura de Fortaleza, 2020).

Outro ponto abordado no questionário buscou saber se os estudantes leem as placas encontradas em cada recinto contendo informações sobre os animais, 86,55\% afirmaram que sim e 3,44\% que não. Diante de muitas descrições semelhantes entre os discentes, há a resposta destacada pelo Aluno 2 que "as placas são uma forma de apresentação dos animais e de adquirir informações sobre eles, porém, em algumas, o conteúdo é bem restrito, podendo comprometer o objetivo da educação ambiental. Trazer informações sobre habitat natural, sua distribuição cosmopolita ou endêmica e grau de ameaça, pode enriquecer muito mais essas ferramentas e ser mais eficaz na conscientização da sociedade".

No Zoológico Municipal Sargento Prata há placas informativas nos recintos, e apesar de conter informações sucintas, informam bem o visitante leigo, sendo isto uma exigência que consta na Instrução Normativa $N^{\circ} 07$ de 30 de abril de 2015 do Ibama, a saber: "manter, em cada recinto sujeito à visitação pública, uma placa informativa onde constem, no mínimo, os nomes comum e científico das espécies dos espécimes ali expostas, a sua distribuição geográfica e a indicação quando se tratar de espécies ameaçadas de extinção" (Brasil, 2015). Esta, infelizmente, não é a realidade de todos os zoológicos. Artigas e Fischer (2019) alertam em seu trabalho, para a necessidade de cartazes/placas informativas e interativas não só nos recintos, contendo informações sobre a natureza, habitat e nicho ecológico do animal, mas também que os visitantes não devem ofertar alimento aos animais no Zoológico.

No entanto, é relatado que a leitura das placas nem sempre é um comportamento efetivado pelos visitantes (Aragão, 2014; Marchand et al., 2017), diferente do que foi visto positivamente nesta pesquisa. Segundo Tomas, Crompton e Scott (2003), os visitantes possuem preferência por estímulos visuais e interativos atribuído de sons e movimentos, e acabam não se interessando pelas informações das placas informativas.

Com base no questionamento final, verificou-se que 100\% dos discentes ficaram satisfeitos com a visita ao zoológico. Diante das justificativas, é possível notar que souberam identificar de forma geral as funções desenvolvidas pelo zoológico e reconhecer a importância de se preservar as espécies que se encontram vulneráveis ou incapazes. Além disso, há a questão do reflexo dessa satisfação na construção do aprendizado dos estudantes, o que também pode ser evidenciado por Prado e Teotonio (2020) ao analisarem visitas de 920 dos 1041 alunos da disciplina de biologia, do curso de Psicologia do Centro Universitário do Distrito Federal, no Zoológico de Brasília, e constatarem melhor desempenho nas avaliações da disciplina dos discentes que fizeram a visita em relação aos que não fizeram.

\section{Considerações Finais}

A pesquisa trouxe informações sobre a percepção de discentes do Curso de Licenciatura em Ciências Biológicas da Universidade Estadual do Ceará, realizado em ambiente não-formal, no caso o Zoológico Municipal Sargento Prata, já visitado pela maior parte dos estudantes, principalmente acompanhados pela família e indicando este espaço como um importante atrativo e contribuinte para o lazer.

As informações coletadas neste estudo com base nas impressões e constatações dos participantes, reforçam os objetivos dos zoológicos como fonte de proteção, conservação e bem-estar animal, educar ambientalmente seus diferentes públicos de visitantes, propiciar pesquisas científicas e a disponibilidade destas para os frequentadores, além de lazer e recreação.

A promoção deste tipo de atividade prática dentro de um curso da área ambiental é de extrema importância para que os futuros profissionais possam conhecer e aprender o papel e a rotina dos zoológicos, aproximando-se da realidade e dos desafios encontrados nestes ambientes, que podem fornecer benefícios e formar cidadãos mais conscientes com as questões 
ambientais.

A partir disso, sugere-se que novos estudos em diferentes âmbitos e níveos do Ensino sejam desenvolvidos, para que se possa melhor identificar a percepção de diferentes alunos e/ou público visitantes de zoológicos, estimulando o conhecimento e aproximação da comunidade geral nestes ambientes, assim como impulsionar e despertar os objetivos dos zoológicos para futuros profissionais da área, como foi o caso do público deste trabalho.

\section{Referências}

Affonso, E. J. D., Flores, L. M. C., Silva, M. P., Oliveira, R. M., Gomes. R. \& Bendassolli, M. C. N. F. (2015). Um relato de experiência sobre a importância do trabalho do profissional biólogo no Zoológico Municipal de São Paulo. Caderno Magsul de Ciências Biológicas, 4(3), 25-30.

Antunes, L. R., Costa, A. C. F., Silva, L. A. L., Oliveira, M. X. L. \& Neto, F. F. P. (2017). Percepção ambiental de visitantes do Zoológico de Recife. Anais da Semana de Zootecnia da UFRPE, Recife, PE, 25.

Aragão, G. M. O. (2014). Percepção ambiental de visitantes do Zoológico de Brasília-DF. 98 f. Dissertação (Mestrado em Agroecossistemas) - Universidade Federal de Santa Catarina, Florianópolis.

Artigas, N. A. S. \& Fischer, M. L. (2019). Limitações o cativeiro quanto a promoção de bem-estar em primatas na percepção do visitante do zoológico de Curutiba. Revbea, 14(2), 49-68.

Azevedo, C. S. \& Barçante, L. (2018). Enriquecimento ambiental em zoológicos brasileiros: em busca do bem-estar animal. Zoociências, 19 (2), 15-34.

Balleste, S. (2019). Preferência por animais em jardins zoológicos: o caso do Parque Zoológico da FZB/RS. Acta Scientiarum. Human and Social Sciences, 41(2), 1-10

Bardin, L. (2016). Análise de conteúdo. Edições 70.

Berico, G. dos S., Peixoto, A. C., Pires, M. V., Silva, L. I. de O. \& Amaral, M. C. (2018). Arara vermelha (Ara chloroptera) no Zoológico de Goiânia. Anais da Mostra de Produção Técnico Científica do Curso de Medicina Veterinária.

Brasil, C. C., Oliveira, P. R. S. \& Vasconcelos, A. P. S. M. (2017). Perfil e trajetória profissional dos egressos de residência multiprofissional: trabalho e formação em saúde. Sanare, 16(1), 60-66.

Brasil. (1983). Lei $N^{o} 7.173$, de 14 de dezembro de 1983. Dispõe sobre o estabelecimento e funcionamento de jardins zoológicos, e dá outras providências. Brasília, DF: Diário Oficial da União.

Brasil. (2015). Instrução normativa Ibama $N^{o} 07$, de 30 de abril de 2015. Institui e normatiza as categorias de uso e manejo da fauna silvestre em cativeiro, e define, no âmbito do IBAMA, os procedimentos autorizados para as categorias estabelecidas. Brasília, DF: Diário Oficial da União.

Chaer, G., Diniz, R. R. P. \& Ribeiro, E. A. (2011). A técnica do questionário na pesquisa educacional. Evidência, 7(7), 251-266.

Clayton, S., Fraser, J. \& Saunders, C. D. (2009). Zoo experiences: conversations, connections, and concern for animals. Zoo Biology, $28(5), 377-397$.

Farinon, C. L., Nascimento E. L. do \& Ivankio, R. (2014). Avaliação da prática da educação ambiental no Zoológico Bosque Guarani no município de Foz de Iguaçu - Paraná. 66 f. Trabalho de conclusão de curso (Tecnólogo em Gestão Ambiental) - Universidade Federal do Paraná, Medianeira.

Fischer, M. L., Prohnii, S. S., Artigas, N. A. S. \& Silverio, R. A. (2017). Os zoológicos sob a perspectiva da bioética ambiental: uma análise a partir do estudo de caso dos felídeos cativos. Revista Iberoamericana de Bioética, (4), 1-17.

Goldschmidt, A. I. (2017). Professor, o que fazer no Zoológico? Revista Ciências \& Ideias, 7(3), 60-87.

Gomes, A. (2012). O Jardim Zoológico enquanto espaço não formal para promoção do desenvolvimento de etapas do raciocínio científico. 114 f. Dissertação (Mestrado em Ensino de Ciências) - Universidade de Brasília, Brasília.

Greif, S. (2017). Um pouco de história sobre animais em zoológicos. http://www.projetogap.org.br/noticia/um-pouco-de-historia-sobre-animais-emzoologicos/

Leira, M. H., Reghim, L. S., Cunha, L. T., Ortiz, L. S., Paiva, C. O., Botelho, H. A., Ciacci, L. S., Braz, M. S. \& Dias, N. P. (2017). Bem-estar dos animais nos zoológicos e a bioética ambiental. Pubvet, 11(7), 545-553.

Lima, C. C., Barros, R. A., Valente, B. B. \& Andrande, G. D. S. (2015). Percepção dos visitantes do zoológico sobre educação ambiental. Anais do Encontro de Iniciação Científica e Mostra de Extensão da Unincor, 17, 2.

Lima, M. C. \& Bosa, C. R. (2016). Percepção ambiental de pais e filhos visitantes de parques na cidade de Curitiba. Revista Eletrônica do Mestrado de Educação Ambiental, 33(1), 327-344.

Marchand, G. A. E. L., Gomes, A. L. S., Pereira, H. S. \& Lima, V. T. A. (2017). É possível (re)conectar o público escolar do Zoológico do Centro de Instrução de Guerra na Selva (Manaus, Amazonas) à fauna amazônica? In G. A. E. L. Marchand \& F. V. Velden (Orgs.), Olhares cruzados sobre as relações entre seres humanos e animais silvestres na Amazônia (Brasil, Guiana Francesa). Edua.

Marin, Y. A. O., Carvalho, Y. K. \& Freitas, A. M. F. (2017). Escolas e Zoológicos: uma relação de continuidade no ensino da biologia e na Educação Ambiental. Anais do Encontro Nacional de Pesquisa em Educação em Ciências, 11. 
Martins, M. C. (2012). Educação e ambiente: a relação entre humanos e não humanos em zoológicos urbanos. 91 f. Dissertação (Mestrado em Educação) Faculdade de Educação, Pontifícia Universidade Católica do Rio Grande do Sul.

Martins, V. N. B. (2018). Enriquecimento ambiental para Leopardus tigrinus Schreber, 1775 (Carnivora, Felidae) no Zoológico Municipal de Uberlândia, Uberlândia, MG. 28 f. Trabalho de conclusão de curso (Ciências Biológicas) - Universidade Federal de Uberlândia.

Nojoza, E. G. (2019). Panorama do bem-estar animal nos zoológicos do Ceará. 66 f. Trabalho de conclusão de curso (Ciências Biológicas) - Universidade Federal do Ceará, Fortaleza.

O Povo. (2017). Um ano após ser reaberto, Zoológico Municipal é opção de lazer gratuito. https://www.opovo.com.br/noticias/fortaleza/2017/06/zoologicomunicipal-completa-um-ano-como-opcao-de-lazer-em-fortaleza.html

O Povo. (2019). Zoológico Municipal Sargento Prata abriga mais de 30 espécies resgatadas neste ano. https://www.opovo.com.br/noticias/2019/11/27/zoologico-municipal-sargento-prata-abriga-mais-de-30-especies-resgatadas-neste-ano.html

Orso, J., Ferreira, A. S. \& Kufner, D. E. (2017). Ecoturismo e conservação ambiental: proposta de projeto para um jardim zoológico em Chapecó (SC). Anais do Anuário Pesquisa e Extensão Unoesc Xanxerê, Chapecó, SC, 2.

Patrick, P. G., Matthews, C. E., Ayers, D. F. \& Tunnicliffe, S. D. (2007). Conservation and Education: Prominent Themes in Zoo Mission Statements. The Journal of Environmental Education, 38(3), 53-60.

Pivelli, S. R. P. (2006). Análise do potencial pedagógico de espaços não formais de ensino para o desenvolvimento da temática da biodiversidade e sua conservação. 165 f. Dissertação (Mestrado em Educação) - Faculdade de Educação, Universidade de São Paulo, São Paulo.

Prado, C. C. \& Teotonio, W. S. (2020). Uso de metodologia ativa no ensino do comportamento animal, no curso de psicologia. Revista Thema, 17 (1), 35-44.

Prefeitura de Fortaleza. (2016). Prefeitura reabre Zoológico Sargento Prata requalificado. https://www.fortaleza.ce.gov.br/noticias/prefeitura-reabrezoologico-sargento-prata-requalificado

Prefeitura de Fortaleza. (2018). Horto Florestal Municipal. https://www.fortaleza.ce.gov.br/noticias/tag/Horto\%20Florestal\%20Municipal

Prefeitura de Fortaleza. (2019). Zoológico Municipal Sargento Prata recebe mais de 70 animais em 2019. https://www.fortaleza.ce.gov.br/noticias/zoologicomunicipal-sargento-prata-recebe-mais-de-70-animais-em-2019-2

Prefeitura de Fortaleza. (2020). Zoológico intensifica cuidados com os animais e anuncia nascimento de uma arara-vermelha em meio à pandemia. https://www.fortaleza.ce.gov.br/noticias/zoologico-intensifica-cuidados-com-os-animais-e-anuncia-nascimento-de-uma-arara-vermelha-em-meio-a-pandemia

Prodanov, C. C. \& Freitas, E. C. (2013). Metodologia do trabalho científico: Métodos e técnicas da pesquisa e do trabalho acadêmico (2a ed.). Rio Grande do Sul: Editora da Universidade Freevale.

Robinette, C., Saffran, L. \& Ruple, A.; Deem, S. L. (2017). Zoos and public health: A partnership on the One Health frontier. One Health, 3 , 1-4.

Rosa, P. R. S. (2010). Instrumentos para o Ensino de Ciências. Campo Grande: Editora da UFMS.

Saraiva, R. V. (2017). O zoológico como um espaço de ciência para a sensibilização de estudantes sobre a temática biodiversidade brasileira. 89 f. Dissertação (Mestrado em Educação) - Faculdade de Educação, Universidade Federal de Minas Gerais, Belo Horizonte.

Silva, A. da. (2019). Importância dos zoológicos visando o bem-estar de animais silvestres exóticos. 24 f. Trabalho de conclusão de curso (Medicina Veterinária) - Centro Universitário do Planalto Central Apparecido dos Santos, Gama.

Silva, C. C. (2016). Análise da percepção ambiental de visitantes do Parque Zoobotânico Arruda Câmara (PZAC - BICA), João Pessoa - Paraíba - Brasil. 60 f. Trabalho de conclusão de curso (Ciências Biológicas) - Universidade Estadual da Paraíba, João Pessoa.

Silva, M. A. (2018). Avaliação de dietas de jaguatiricas (Leopardus pardalis) no Zoológico Sargento Prata. 57 f. Trabalho de conclusão de curso (Zootecnia) - Departamento de Zootecnia, Universidade Federal do Ceará, Fortaleza.

Silva, M. C. e. (2017). Quem não é visto, não é lembrado: a valorização do Zoológico Municipal Sargento Prata como atrativo turístico e espaço de lazer em Fortaleza a partir da análise textual dos jornais O Povo e Diário do Nordeste e do discurso do público visitante. $140 \mathrm{f}$. Dissertação (Mestrado em Gestão de Negócios Turísticos) - Universidade Estadual do Ceará, Fortaleza.

Souza, M. V. de, Telles, L. P. J. D., Hirano, L. Q. L., Santos, N. P. dos, Botelho, N. E. G., Silva Junior, P. G. P. da, Moura, M. dos A. \& Batista, M. J. (2020). Zoológico empírico: a nova fronteira entre o ensino e a pesquisa em zoos no Brasil. Pensar Acadêmico, 18(2), 300-321.

Tomas, S. R., Crompton, J. L. \& Scott, D. (2003). Assessing service quality and benefits sought among zoological park visitors. Journal of Park and Recreation Administration, 21(2), 105-124.

Veroneze, A. S., Fernandes, D. R., Almeida, H. S., Silva, E. L. F. \& Borlini, T. C. (2020). Enriquecimento ambiental aplicado a tigres (Pantheratigris) e onças pintadas (Pantheraonca) cativos no Zoológico Zoo Park da Montanha - Marechal Floriano - ES. Atas de Saúde Ambiental, 8, 110-121.

Waza. (2015). Construindo um Futuro para a Vida Selvagem: Estratégia Mundial dos Zoos e Aquários para a Conservação (P. J. S. Olney, Trad.). Lisboa: Jardim Zoológico e de Aclimação em Portugal.

Zago, J. P., Rocha, M. B. \& Costa, I. J. O. (2020). Estudo sobre Percepção Ambiental de Visitantes no Parque Nacional da Tijuca. Research, Society and Development, 9(1), 1-24. 